\title{
Factors Influencing Children's Regular Attendance at Dental Clinics in Al Madinah, Saudi Arabia
}

\author{
Amal Aqeeli $^{a, b}$ Alla T. Alsharif ${ }^{b}$ Estie Kruger ${ }^{a}$ Marc Tennant $^{a}$ \\ anternational Research Collaborative, Oral Health and Equity, School of Human Sciences, The University of \\ Western Australia, Perth, WA, Australia; ${ }^{b}$ Preventive Dental Sciences, Taibah University Dental College and Hospital, \\ Madinah, Saudi Arabia
}

\section{Keywords}

Regular dental visits · Dental check-ups · Adherence ·

Children · Barriers

\begin{abstract}
Objectives: This study aimed to investigate sociodemographic, clinical, and behavioral characteristics of 9- to 12-year-old schoolchildren who attend regular dental visits. Methods: A stratified sample from 10 schools in Al Madinah, SA, was selected, and a total of 1,000 students aged 9-12 years were included in the study. The WHO criteria (2013) for assessing dental caries were used to collect clinical data, and information on dental visits and sociodemographic and behavioral variables was collected through the WHO questionnaire. The logistic regression model was used to examine the relationship between regular dental visits and sociodemographic, clinical, and behavioral factors. Results: Only 9.2\% of the sample reported regular dental visits. The multiple logistic regression model showed that gender (female: $\mathrm{OR}=$ 1.715; $p=0.041$ ), high family income (middle income: OR = $0.464 ; p=0.024$; and low income: $\mathrm{OR}=0.517 ; p=0.015)$, and the consumption of sugary food and drinks (almost daily: $\mathrm{OR}=0.438 ; p=0.017$; and several times a week: $\mathrm{OR}=0.511$; $p=0.050$ ) were associated with regular dental visits after accounting for other sociodemographic and clinical variables
\end{abstract}

karger@karger.com www.karger.com/sjh

Karger!

GOPEN ACCESS
(C) 2021 The Author(s)

Published by S. Karger AG, Basel

This is an Open Access article licensed under the Creative Commons Attribution-NonCommercial-4.0 International License (CC BY-NC) (http://www.karger.com/Services/OpenAccessLicense), applicable to the online version of the article only. Usage and distribution for commercial purposes requires written permission. and other oral health behavior. Conclusion: In the population studied, $<10 \%$ of 9 - to 12 -year-olds made regular annual visits to dental clinics in AI Madinah, SA.

C 2021 The Author(s)

Published by S. Karger AG, Basel

\section{Introduction}

Despite the advancement in dental treatment technologies and preventive methods, dental caries persists as the most prevalent oral disease among children [1]. Visiting the dentist regularly is one of the main oral health behaviors that plays an important role in maintaining oral health for its early detection, intervention, and subsequently, reducing the cost of dental treatment and the burden of disease in the population [2-4].

However, several reasons stand as barriers that prevent some children from visiting the dentist regularly, including dental fear and anxiety, low parental awareness, and lack of accessibility and affordability [5-7]. Socioeconomic and behavioral aspects also influence dental visits. Children from higher socioeconomic status tend to visit the dentist regularly in contrast to children from lower socioeconomic status [8]. Furthermore, health risk behaviors, such as poor diet, smoking, excessive alcohol consumption, and physical inactivity, tend to cluster to- 
gether with irregular dental checkups among the same group of people, specifically disadvantaged people with low socioeconomic rank [9].

Saudi Arabia (SA) is an oil-rich developing country in the Middle East whose population, over the last 60 years, have experienced major changes to their diet, one of which has been an increase in sugar intake. This has been accompanied by a rapid rise in the burden of dental disease, predominantly dental caries [10]. Although dental services are publicly provided and free of charge for the population in SA, the majority of people do not visit the dentist regularly for routine checkups, but only for emergency situations, when they feel pain or discomfort, while only a small proportion of the population visit the dentist regularly [11-13]. A recent study by Alayadi et al. [14] reported that only $6.8 \%$ reported regular dental visits in Riyadh, SA.

Identifying the sociodemographic and behavioral factors that are associated with regular dental visits will help identifying those at greater need for dental services, specifically in SA where affordability is not a barrier to dental health services. Upon our knowledge, this is the first study to identify characteristics of regular dental attenders in Madinah, SA. The aim of this study was to investigate sociodemographic, clinical, and behavioral characteristics of 9- to 12-year-old schoolchildren in Madinah, SA, who visit the dentist regularly.

\section{Materials and Methods}

A cross-sectional community-based study recruited a sample of 1,000 schoolchildren aged 9-12 years, in the city of Al Madinah. $\mathrm{Al}$ Madinah is one of the major cities in SA, with a child (10-14 years old) population of 172,548 [15].

As for the selection of participating schools, a stratified random sampling design was applied, according to 2 levels: high and low socioeconomic levels, based on the school districts' socioeconomic level. Ten schools in the city were selected and included in the survey. Prior to each school visit, information sheets and questionnaires (that included information on sociodemographic variables, family size, parental education level, and occupation) were sent to all parents of 9- to 12-year-olds in the schools to invite participation and obtain consent.

The study used oral health survey data that were gathered by the University of Taibah, Department of Preventive Dental Sciences (DPDS). Four calibrated and trained staff from the DPDS carried out the survey and oral examinations in accordance with the international standards established by the WHO (2013) [16]. Instructors with previous experience in oral health surveys/examination following WHO guidelines directed the training. The percentage of agreement for inter-examiner and intra-examiner reliability for detecting caries was $89 \%$ prior to starting data collection.

All 9- to 12-year-old students who attended the schools on the day of the survey and whose parents provided consent were in-
Self-reported oral health care and behaviors

- How often did you go to the dentist during this year? a) Once. b) Twice. c) Three times. d) Four times or more. e) I have never received dental care. f) I don't know.

-What was the reason for your last visit to the dentist? a) Pain or trouble with teeth or mouth.

b) Treatment/follow-up treatment.

c) Routine check-up of teeth/treatment.

d) I don't know/I don't remember.

- How often do you brush your teeth? a) Irregularly or never. b) Once a week.

c) More than once a week. d) Once a day.

e) More than once a day.

- Do you use fluoride toothpaste when brushing? a) Always. b) Often. c) Rarely. d) Never.

- How often do you eat sugar-containing snacks or drinks between your main meals?

a) Several times a day. b) Almost daily. c) Several times a week. d) Several times a month. e) Rarely or never.

Fig. 1. Self-reported oral health care and behavior questionnaire.

cluded in the survey. Oral examinations were performed using the standardized WHO Oral Health Survey assessment form for oral health surveys [16].

Caries experience was expressed as yes/no for children with/ without any caries experience. Caries severity was assessed by the mean DMFT for the study sample. The Decayed, Missed, and Filled index (DMFT in permanent teeth and dmft in primary teeth) was calculated by adding the number of teeth that was affected by caries (including teeth with untreated caries, filled because of caries, or have been removed because of caries). The significant caries index ( $\mathrm{SiC}$ ) was used and calculated as follows: individuals in the study sample were sorted from the highest to the lowest according to their DMFT values. The mean DMFT of the one-third (30\%) of the sample with the highest DMFT scores was then calculated. The dental care index was defined by the ratio FT/ DMFT [17].

The main outcome in this study was regular dental visit. The questionnaire included questions on dental visits within the past 12 months and the reason for visiting the dentist (routine checkup, pain or trouble with teeth, treatment follow-up, and I do not know). A new binary outcome variable was created with all those who reported regular dental visits as one category and all other responses as a second category (yes and no).

Sociodemographic variables included age, gender, school type, and family occupation. Age was categorized as 2 groups: 9-10 years old and 11-12 years old. The type of school was dichotomized as public or private schools. To determine the level of socioeconomic status, parents' occupations were used as a proxy for family monthly income and divided into 3 categories: low, medium, and high, as described elsewhere [18].

Regular dental visit was examined in relationship with some health risk and health-promoting behaviors that were part of the questionnaire (Fig. 1). These included frequencies of toothbrushing (irregular or never, once a week, more than once a week, once a day, and more than once a day) and use of fluoride toothpaste (always, 
Table 1. Distribution of all variables used in the analysis and regular dental visits among 9- to 12-year-old schoolchildren in Madinah, SA $(n=1,000)$

\begin{tabular}{|c|c|c|c|c|}
\hline \multirow[t]{3}{*}{ Variables } & \multicolumn{3}{|c|}{$(N) \%$ or mean $\pm \mathrm{SD}$} & \multirow[t]{3}{*}{$p$ value } \\
\hline & \multicolumn{3}{|c|}{ regular dental visits } & \\
\hline & total & yes & no & \\
\hline All children & $(1,000) 100$ & 9.2 & 90.8 & \\
\hline \multirow{2}{*}{\multicolumn{5}{|c|}{$\begin{array}{l}\text { Sociodemographic } \\
\text { Age }\end{array}$}} \\
\hline & & & & \\
\hline $9-10$ years & (342) 34.4 & 10.7 & 89.3 & \multirow{2}{*}{0.262} \\
\hline $11-12$ years & (653) 65.6 & 8.5 & 91.5 & \\
\hline \multicolumn{5}{|l|}{ Gender } \\
\hline Male & (601) 60.1 & 6.9 & 93.1 & \multirow{2}{*}{$0.002 *$} \\
\hline Female & 39.9 & 12.8 & 87.2 & \\
\hline \multicolumn{5}{|l|}{ Socioeconomic } \\
\hline \multicolumn{5}{|l|}{ School type } \\
\hline Private & (504) 50.4 & 11.1 & 88.9 & \multirow{2}{*}{$0.038^{*}$} \\
\hline Public & (496) 49.6 & 7.3 & 92.7 & \\
\hline \multicolumn{5}{|l|}{ Family income } \\
\hline Low & (314) 31.9 & 6.1 & 93.9 & \multirow{3}{*}{$0.001^{*}$} \\
\hline Middle & (391) 39.7 & 7.5 & 92.5 & \\
\hline High & (279) 28.4 & 14.8 & 85.2 & \\
\hline \multicolumn{5}{|l|}{ Clinical examination } \\
\hline \multicolumn{5}{|l|}{ Caries experience } \\
\hline Yes & (851) 85.1 & 9.0 & 91.0 & \multirow[b]{2}{*}{0.627} \\
\hline No & (149) 14.9 & 10.3 & 89.7 & \\
\hline Mean dmft & $2.66 \pm 2.64$ & $2.22 \pm 2.77$ & $2.70 \pm 2.60$ & 0.098 \\
\hline Mean DMFT & $1.43 \pm 1.73$ & $1.48 \pm 1.74$ & $1.43 \pm 1.78$ & 0.191 \\
\hline Significant caries index & $3.52 \pm 1.572$ & $3.75 \pm 1.066$ & $3.50 \pm 1.618$ & 0.470 \\
\hline Dental care index & $0.07 \pm 0.23$ & $0.09 \pm 0.25$ & $0.06 \pm 0.23$ & 0.306 \\
\hline \multicolumn{5}{|c|}{ Self-reported oral health care and behaviors } \\
\hline \multicolumn{5}{|c|}{ Frequency of tooth brushing } \\
\hline Irregular or never & (152) 15.3 & 7.2 & 92.8 & \multirow{5}{*}{0.772} \\
\hline Once a week & (76) 7.6 & 9.3 & 90.7 & \\
\hline More than once a week & (155) 11.6 & 8.7 & 91.3 & \\
\hline Once a day & 23.1 & 8.4 & 91.6 & \\
\hline More than once a day & (422) 42.4 & 10.5 & 89.5 & \\
\hline \multicolumn{5}{|l|}{ Use of fluoridated toothpaste } \\
\hline Yes & (925) 92.5 & 9.8 & 90.2 & \multirow{2}{*}{$0.005^{*}$} \\
\hline No & (75) 7.5 & 1.4 & 98.6 & \\
\hline \multicolumn{5}{|c|}{ Consumption of sugary food and drinks } \\
\hline Several times a day & (222) 22.2 & 7.8 & 92.2 & \multirow{5}{*}{0.060} \\
\hline Almost daily & (242) 24.2 & 6.6 & 93.4 & \\
\hline Several times a week & (212) 21.2 & 7.7 & 92.3 & \\
\hline Several times a month & (107) 10.7 & 12.4 & 87.6 & \\
\hline Rarely or never & (217) 21.7 & 13.5 & 86.5 & \\
\hline
\end{tabular}

* Statistically significant at $p$ value $<0.05$ from the $\chi^{2}$ or $t$ test.

often, and rarely or never), but the latter was dichotomized to yes and no because there was not enough number of responses in each category. There was also a question on the frequency of consumption of sugary foods and drinks (several times a day, almost daily, several times a week, several times a month, and rarely or never).

Regular dental visit was analyzed across sociodemographic, clinical, and self-reported oral health variables. The difference be- tween groups was assessed by using Student's $t$ test or $\chi^{2}$, and significance levels were set at $95 \%$. The logistic regression model was carried out with regular dental visit as a dependent variable adjusting for gender, age, family monthly income, mean DMFT, dental care index, and oral health behavior variables. Software used for data entry and all statistical tests was IBM SPSS software (ver.25.0; IBM, Chicago, IL, USA). 
Table 2. Results of multivariable logistic regression of the association between regular dental visits and explanatory variables among 9- to 12-year-old schoolchildren in Madinah, SA $(n=1,000)$

\begin{tabular}{|c|c|c|c|c|}
\hline Variables & $B$ & Wald & OR $(95 \% \mathrm{CI})$ & $p$ value \\
\hline \multicolumn{5}{|l|}{ Age } \\
\hline $9-10$ years & & & 1 & \multirow{2}{*}{0.646} \\
\hline $11-12$ years & 0.127 & 0.211 & $1.135(0.661-1.974)$ & \\
\hline \multicolumn{5}{|l|}{ Gender } \\
\hline Male & & & 1 & \multirow{2}{*}{$0.041^{*}$} \\
\hline Female & 0.539 & 4.165 & $1.715(1.022-2.878)$ & \\
\hline \multicolumn{5}{|l|}{ Socioeconomic } \\
\hline \multicolumn{5}{|l|}{ School type } \\
\hline Private & & & 1 & \multirow{2}{*}{0.393} \\
\hline Public & 0.241 & 0.731 & $1.273(0.732-2.211)$ & \\
\hline \multicolumn{5}{|l|}{ Family income } \\
\hline High & & & 1 & \\
\hline Middle & -0.767 & 5.106 & $0.464(0.239-0.903)$ & $0.024^{*}$ \\
\hline Low & -0.660 & 5.889 & $0.517(0.303-0.881)$ & $0.015^{*}$ \\
\hline \multicolumn{5}{|l|}{ Clinical examination } \\
\hline Mean DMFT & 0.119 & 3.019 & $1.126(0.985-1.287)$ & 0.082 \\
\hline Mean dental care index & 0.271 & 0.370 & $1.312(0.547-3.146)$ & 0.543 \\
\hline Mean dmft & -0.045 & 0.890 & $0.956(0.869-1.050)$ & 0.345 \\
\hline \multicolumn{5}{|c|}{ Self-reported oral health care and behaviors } \\
\hline \multicolumn{5}{|l|}{ Frequency of tooth brushing } \\
\hline Irregular or never & 0.055 & 0.022 & $1.056(0.510-2.187)$ & 0.882 \\
\hline Once a week & 0.079 & 0.041 & $1.102(0.433-2.804)$ & 0.839 \\
\hline More than once a week & -0.196 & 0.245 & $0.822(0.379-1.783)$ & 0.620 \\
\hline Once a day & -0.109 & 0.135 & $0.896(0.500-1.608)$ & 0.714 \\
\hline More than once a day & & & 1 & \\
\hline \multicolumn{5}{|l|}{ Use of fluoridated toothpaste } \\
\hline Yes & -1.926 & 3.515 & $0.146(0.019-1.091)$ & \\
\hline No & & & 1 & 0.061 \\
\hline \multicolumn{5}{|c|}{ Consumption of sugary food and drinks } \\
\hline Several times a day & -0.472 & 1.980 & $0.623(0.323-1.204)$ & 0.159 \\
\hline Almost daily & -0.826 & 5.653 & $0.438(0.222-0.865)$ & $0.017^{*}$ \\
\hline Several times a week & -0.670 & 3.853 & $0.511(0.262-0.999)$ & $0.050^{*}$ \\
\hline Several times a month & -0.040 & 0.011 & $0.961(0.462-2.000)$ & 0.915 \\
\hline Rarely or never & & & 1 & \\
\hline
\end{tabular}

* Statistically significant at $p$ value $\leq 0.05$.

\section{Results}

Data analysis was conducted on 1,000 schoolchildren who had complete data. The final response rate was $83.3 \%$. Only $9.2 \%$ of the sample reported regular routine dental visits. Table 1 presents the distribution of all variables used in the analysis and regular dental visits. More than half of the participants were between 11 and 12 years old. The study population included $39.9 \%$ of female and $60.1 \%$ of male participants. Regular dental visits were $12.8 \%$ and $6.9 \%$ within females and males, respectively.

Among sociodemographic variables, the percentage of children who reported regular dental visits was lowest among those from families with low income (6.1\%) and highest among those from families with high income $(14.8 \%)$. Among self-reported oral health care and behavior, the percentage of children who reported regular dental visits was lowest among those who do not use fluoridated toothpaste (1.4\%) and highest among those who rarely or never eat sugary food and drinks (13.5\%).

The percentage of females who reported regular dental visits was higher than males $(12.8 \%$ vs. $6.9 \%$; $p=$ $0.002)$. Schoolchildren who come from families with low income reported lower regular dental visits compared to schoolchildren from families with middle and high income $(6.1 \%, 7.5 \%$, and $14.8 \%$, respectively; $p=0.001)$. 
The percentage of schoolchildren who were at private schools and reported regular dental visits was higher than those who were at a public school $(11.1 \%$ vs. $7.3 \%$; $p=0.038)$. The percentage of children who reported regular dental visits was higher among those who used fluoridated toothpaste $(9.8 \%$ vs. $1.4 \% ; p=0.005)$. After adjusting for sociodemographic, behavioral, and clinical variables, gender (female: $\mathrm{OR}=1.715 ; p=0.041$ ), family income (middle income: $\mathrm{OR}=0.464 ; p=0.024$; and low income: $\mathrm{OR}=0.517 ; p=0.015$ ), and consumption of sugary food and drinks (almost daily: $\mathrm{OR}=0.438 ; p=0.017$; and several times a week: $\mathrm{OR}=0.511 ; p=0.050$ ) were associated with regular dental visits (Table 2).

\section{Discussion}

In the current study, we used 9- to 12-year-old schoolchildren data from 10 randomly selected primary schools in Madinah, SA, to examine the relationship between regular dental visits and sociodemographic, clinical, and self-reported oral health behavior. Regular dental visit had higher probabilities among schoolchildren who were female, from families with higher income, and who had low consumption of sugary food and drinks, after accounting for other sociodemographic variables and clini$\mathrm{cal}$ and other oral health behavior.

The total percentage of regular dental visits among the study sample was noticeably low (9.2\%). This percentage was relatively smaller than that reported by El Bcheraoui et al. [19] and Alhumiad et al. [13] (11.5\% and $14.4 \%$, respectively). Nevertheless, the overall frequency of regular dental visits among Saudi population is considered low despite the availability of free of charge dental health services $[14,20]$. On the other hand, symptomatic dental visit is more common among the Saudi population [13]. This irregular pattern of the use of dental health services adds up to the high prevalence of untreated dental caries in the population where it persists as the main dental health problem among Saudi children [10].

The low occurrence of regular dental visits could be attributed to fear or anxiety of dental treatment which is one of the most common barriers to the regular use of dental services [6]. In a cross-sectional study among middle school children in 2014, Gaffar et al. [21] found that dental fear was associated with irregular dental visits. In another study, lack of time, cost, far-situated dental services, and fear were the most prevalent barriers of regular dental visits. Furthermore, parents' lack of awareness is another common reason that prevents children from going to the dentists [7]. Alshammary et al. [22] reported that $58.3 \%$ of the respondents stated that they would take their children to the dentist only if the child has pain, while only $13 \%$ of parents stated that they would take their children to the dentist twice a year. Females were more likely to visit the dentist regularly than males, and this agrees with the literature from different parts of the world, including Australia, Germany, and the USA [2325].

In addition, consistent with the literature, this research found that socioeconomic condition was significantly related to regular dental visits in that higher family income was associated with regular dental visits $[26,27]$. This disparity in the regular dental visits among Saudi children despite the availability of free services exposes indirect socioeconomic barriers such as taking time off work, transportation fees, and waiting time in the dental clinic [28]. In addition, among people from low socioeconomic status, other health conditions could take more priority over routine dental visits.

Among the self-reported oral health behaviors that were examined in this study, the consumption of sugary food and drinks was inversely associated with the probability of visiting the dentists regularly. This result supports evidence from previous observation where regular dental visit was associated with other health-promoting behavior including diet [14]. More than a half of the study population brushed their teeth once per day only or less (57.6\%) that is comparable to Sri Lanka; however, in Australia, the majority of the population brushed their teeth twice or more per day $[29,30]$.

The free delivery of dental care in SA through the Ministry of Health's primary health-care centers and hospitals is not promoting routine dental visits nor eliminating social inequality in the use of the dental services regularly. In contrast to schoolchildren in other countries where they have free oral health care for children under the age of 18 , regular annual attendance at dental clinics is very high: Denmark (78\%), Germany (77\%), and Sweden $(71 \%)[31,32]$.

The findings of this study identified behavioral and sociodemographic characteristics of those who regularly visit the dentist which could help in developing specific strategy to promote regular dental visits among the population. It suggests that children who are males, from low socioeconomic families, and those who consume sugary food and drinks are at risk to be considered as important target groups when health professionals define oral health priorities and health promotion campaigns. 
It is recommended for future studies to examine underlying barriers to the use of dental services including the use of geographic analysis to assess distribution and accessibility of the dental services [33] and to develop specific intervention to promote routine dental visits. These findings may be somewhat limited by the cross-sectional nature of this study which does not support temporality nor causality. It is important to bear in mind that the study sample was restricted to 9- to 12-year-old primary schoolchildren in Al Madinah city, which is worth cautioning in generalizing the results to the entire country. However, considering the cultural homogeneity and urbanity of the area, we would expect our estimates to be relevant to the general child population in SA. We have used self-reported data and father's and mother's occupations as a proxy for family income; this could introduce bias.

\section{Conclusion}

Lack of regular dental visiting is a common behavior among 9- to 12-year-old schoolchildren in Al Madinah, SA, despite the free of charge dental services delivered by the MOH. While there were statistically significant differences between some groups, regular dental care is uncommon in all groups, and interventions should take this into account.

\section{Acknowledgments}

The authors would like to thank the Department of Preventive Dental Sciences at Taibah University Dental College and Hospital for its effort during data collection and Taibah University, Saudi Arabia, for sponsoring Amal's PhD studies.

\section{Statement of Ethics}

Ethical approval to access the de-identified oral health survey data was obtained from the Taibah University Ethics Committee in Al Madinah, SA (TUCDREC/20I 70305/Bakeer). In addition, ethical clearance from the University of Western Australia Ethics Committee was attained (RA/4/20/5476). The study was conducted in accordance with the principles of World Medical Association of Helsinki. Children's parents' consent was obtained alongside child assent from those who were willing to participate prior to the interview. Participation in the study was voluntary, and every questionnaire/examination was anonymous.

\section{Conflict of Interest Statement}

The authors declare no conflicts of interest.

\section{Funding Sources}

Funding was provided by Taibah University.

\section{Author Contributions}

A.A. was the principal investigator for this study, proposed the study design, reviewed the literature, analyzed the data, interpreted the results, and wrote the manuscript draft. A.T.A., E.K., and M.T. revised and critically commented on the manuscript draft and approved the final draft of the manuscript.

\section{Data Availability Statement}

The data that support the findings of this study are available from the Department of Preventive Dental Sciences at Taibah University Dental College and Hospital, Taibah University, Saudi Arabia, upon reasonable request.

\section{References}

1 Do LG. Distribution of caries in children: variations between and within populations. J Dent Res. 2012;91(6):536-43.

2 Sen AB, Blackburn J. Effectiveness of preventive dental visits in reducing nonpreventive dental visits and expenditures. Pediatrics. 2020;131(6):1107-13.

3 Righolt AJ, Jevdjevic M, Marcenes W, Listl S. Global-, regional-, and country-level economic impacts of dental diseases in 2015. J Dent Res. 2018;97(5):501-7.

4 Langevin SM, Michaud DS, Eliot M, Peters ES, McClean MD, Kelsey KT. Regular dental visits are associated with earlier stage at diagnosis for oral and pharyngeal cancer. Cancer Causes Control. 2012;23(11):1821-9.
5 Locker D, Maggirias J, Quiñonez C. Income, dental insurance coverage, and financial barriers to dental care among Canadian adults. J Public Health Dent. 2011;71(4):327-34.

6 Sohn W, Ismail AI. Regular dental visits and dental anxiety in an adult dentate population. J Am Dent Assoc. 2005;136(1):58-1.

7 Badri P, Saltaji H, Flores-Mir C, Amin M. Factors affecting children's adherence to regular dental attendance: a systematic review. J Am Dent Assoc. 2014;145(8):817-28. http://doi: 10.14219/jada.2014.49.

8 Tchicaya A, Lorentz N. Socioeconomic inequalities in the non-use of dental care in Europe. Int J Equity Health. 2014;13(1):714.
9 Kino S, Bernabé E, Sabbah W. Socioeconomic inequality in clusters of health-related behaviours in Europe: latent class analysis of a cross-sectional European survey. BMC Public Health. 2017;17(1):497-8.

$10 \mathrm{Al}$ Agili DE. A systematic review of population-based dental caries studies among children in Saudi Arabia. Saudi Dent J. 2013; 25(1):3-11.

11 Al Agili DE, Farsi NJ. Need for dental care drives utilisation of dental services among children in Saudi Arabia. Int Dent J. 2020;70: 183-92.

12 Murshid EZ. Children's ages and reasons for receiving their first dental visit in a Saudi community. Saudi Dent J. 2016;28(3):142-7. 
13 AlHumaid J, El Tantawi M, AlAgl A, Kayal S, Al Suwaiyan Z, Al-Ansari A. Dental visit patterns and oral health outcomes in Saudi children. Saudi J Med Med Sci. 2018;6(2):89.

14 Alayadi H, Bernabé E, Sabbah W. Examining the relationship between oral health-promoting behavior and dental visits. Int J Health Sci. 2019;13(3):40-3. Available from:

15 General Authority for Statistics in Kingdom of Saudi Arabia. Population characteristics surveys. 2017 [cited 2020 Apr 20]. Available from: https://www.stats.gov.sa/en/5655.

16 World Health Organization. Oral health surveys: basic methods. 5th ed. Geneva, Switzerland: World Health Organization; 2013.

17 Antunes JL, Peres MA, de Campos Mello TR, Waldman EA. Multilevel assessment of determinants of dental caries experience in Brazil. Community Dent Oral Epidemiol. 2006; 34(2):146-52.

18 Kassim S, Bakeer H, Alghazy S, Almaghraby Y, Sabbah W, Alsharif A. Socio-demographic variation, perceived oral impairment and oral impact on daily performance among children in Saudi Arabia. Int J Environ Res Public Health. 2019;16(14):2450.

19 El Bcheraoui C, Tuffaha M, Daoud F, Kravitz $\mathrm{H}$, Almazroa MA, Al Saeedi M, et al. Use of dental clinics and oral hygiene practices in the Kingdom of Saudi Arabia, 2013. Int Dent J. 2016;66(2):99-104
20 Al-Jaber A, Da'ar OB. Primary health care centers, extent of challenges and demand for oral health care in Riyadh, Saudi Arabia. BMC Health Serv Res. 2016;16(1):628-8.

21 Gaffar BO, Alagl AS, Al-Ansari AA. The prevalence, causes, and relativity of dental anxiety in adult patients to irregular dental visits. Saudi Med J. 2014;35(6):598-603.

22 Alshammary F, Aljohani FA, Alkhuwayr FS, Siddiqui AA. Measurement of parents' knowledge toward oral health of their children: An observational study from Hail, Saudi Arabia. J Contemp Dent Pract. 2019;20(7): 801-5.

23 Slack-Smith LM, Mills CR, Bulsara MK, O'Grady MJ. Demographic, health and lifestyle factors associated with dental service attendance by young adults. Aust Dent J. 2007; 52(3):205-9.

24 Brzoska P, Erdsiek F, Waury D. Enabling and predisposing factors for the utilization of preventive dental health care in migrants and non-migrants in Germany. Front Public Health. 2017;5:1-7.

25 Chen M, Wright CD, Tokede O, Yansane A, Montasem A, Kalenderian E, et al. Predictors of dental care utilization in north-central Appalachia in the USA. Community Dent Oral Epidemiol. 2019;47(4):283-90.

26 Shaban R, Kassim S, Sabbah W. Socioeconomic inequality in the provision of specific preventive dental interventions among children in the UK: children's dental health survey 2003. Br Dent J. 2017;222(11):865-9.
27 Sohn W, Ismail A, Amaya A, Lepkowski J. Determinants of dental care visits among lowincome African-American children. J Am Dent Assoc. 2007;138(3):309-98.

28 Percac-Lima S, Aldrich LS, Gamba GB, Bearse AM, Atlas SJ. Barriers to follow-up of an abnormal Pap smear in Latina women referred for colposcopy. J Gen Intern Med. 2010; 25(11):1198-204.

29 Ekanayake L, Ando Y, Miyazaki H. Patterns and factors affecting dental utilisation among adolescents in Sri Lanka. Int Dent J. 2001; 51(5):353-8.

30 John JR, Mannan H, Nargundkar S, D'Souza M, Do LG, Arora A. Predictors of dental visits among primary school children in the rural Australian community of Lithgow. BMC Health Serv Res. 2017;17(1):264-10.

31 European Commission. Special eurobarometer 330: oral health. 2009. Available from: https: //data.europa.eu/data/datasets/ s795_72_3_ebs330?locale=en.

32 Schulte A, Rossbach R, Tramini P. Association of caries experience in 12-year-old children in Heidelberg, Germany, and Montpellier, France, with different caries preventive measures. Community Dent Oral Epidemiol. 2001;29(5):354-61.

33 Alsharif A, Tennant M, Kruger E. Identifying and priotirising areas of child dental services need: a GIS-based approach. Community Dent Health. 2016;33(1):33-8. 